\title{
The Impact of School District on Housing Prices: Based on an Evolutionary Game Model
}

\author{
Chen $\operatorname{Lin}^{1, a^{*}}$ \\ ${ }^{1}$ School of Economics, Sichuan University, Chengdu, Sichuan Province, China \\ a *seventeen17@163.com
}

\section{Keywords: School-district factor; Housing prices; Price penalty coefficient; Evolutionary Game}

\begin{abstract}
This paper focuses on the role that school district plays in the formation of housing prices. Under the nearby-admission policy and Hukou system, housing in a school district is equivalent to housing with admission-ticket function. For households who purchase school-district housing, it is the high-quality primary education that they essentially purchase. The value of schooldistrict factor can be measured theoretically by the increasing part of students' expected income resulting from the improvement of educational quality. But it is hard to exactly obtain. By using selection fees to substitute the increase part of expected income, I establish an evolutionary game model to describe the formation of school-district housing prices. A school-district housing price penalty coefficient and its algorithm are proposed. The coefficient can be used to compare the difference of the extents the school district impact on housing prices in different regions. And a practical example is illustrated. The paper makes contribution to two aspects: It adopts evolutionary game theory to study households' behaviors and housing prices; It provides a feasible approach to analyzing a sole factor's impact on housing prices.
\end{abstract}

\section{Introduction}

In the past two decades, with the rapid development of urbanization in China, commercial housings have been widely built and now become the main property for households. In general, the rise and fall of housing prices are important indicators of macroeconomics. They reveal the status of economy and reflect expectations of the public on markets. From a micro perspective, the changes of housing prices link the basic unit, family, of a society. Housing prices' changes directly reflect the increase or decrease of households' wealth, and influence households' behaviors in investment and consumption. All in all, commercial housing prices are significant, comprehensive and sensitive indicators of both economy and society. According to studies on the formation of commercial housing prices, it has been found that the prices relate to several factors including regional economic development, regulation on housing markets, housing location, area, construction quality, developers' reputation and surrounding public facilities. This paper focuses on the impact of school district on commercial housing prices. In China, the fundamental social regulation system is called Hukou. A series of policies on Hukou control population migration through regions in China. One way to migrate from one region to another is purchasing housing in that region (called Luohu in Chinese). Under the policies of nearby admission, primary nine-year compulsory education are provided in accordance with the residence of students' Hukou. Children who have Hukou in a specific region are qualified to free entry into the corresponding primary and secondary schools. This admission policy is equivalent to endow the commercial housing with a special function, like an "admission ticket". The housing with "admission ticket" function is called school-district housing (called Xuequ Fang in Chinese). In recent years, households have raised increasingly concerns about school-district housing. In the first-tier cities, it is no longer news that small and dilapidated school-district housing are sold out at incredibly high prices. Obviously it is not the residential function but the school district function - the housing correspond to high-quality primary and secondary schools - that attracts purchasers. So on earth what role does school district play in the formation of housing prices? Can the impact be quantified? The following attempts to answer these two questions. 
School district is essentially a public facility affiliated to housing. Studies on the impacts of public service and resource on housing prices trace back to Tiebout (1956) who finds that households' preference for their residence places show their preference for corresponding residential public goods. Then Oates (1969) uses a cross-sectional econometric model to study the impact of regional housing tax and expenditure on public goods on housing prices. From then on, studies regarding the impact of educational resources on housing prices emerge. Black (1999) builds a Hedonic model and uses schools' surrounding housing prices to infer the evaluation of parents on schools' quality. He finds that every $5 \%$ increase of children' performance in test scores leads to $2.5 \%$ increase of housing prices that parents are willing to endure. Brasington (2002) proves that taxation and public services have been already capitalized in housing prices. Due to the large elasticity of housing supply at the urban borders, effects of education capitalization weaken when approaching cities' borders. Chin and Foong (2006) use a Hedonic model to study the impact of accessibility to schools (especially the accessibility to high-quality schools) on housing prices. They find that the accessibility to high-quality schools does affect the surrounding housing prices. Davidoff and Leigh (2008) study the relationship between housing prices and the quality of national schools in Australian Capital territory. In order to control other variables that affect housing prices except for schools, they select housing on two sides of a street which divides the two sides into two high school districts. They find that every 5\% increase in students' test scores results in a 3.5\% increase in housing prices. Besides foreigner studies, Chinese scholars also conduct many researches on the relationship between educational resources and housing prices. WEN Hai-zhen et al. (2013) adopt a logarithmic Hedonic model to study the impact of educational facilities on residential housing prices in Hangzhou, so as to evaluate the capitalization of educational facilities in housing prices. MA Jun et al. (2013) construct a semi-logarithmic Hedonic model to study the impact of the density of primary educational resources on housing prices in Maanshan. FENG Hao and LU Ming (2010) use a Hedonic model to study the impact of educational resources on school district housing prices in Shanghai. Although there are many literatures about the impact of educational resources on housing prices, there are rare researches adapt game theory as analysis method, not to mention evolutionary game theory. In addition, there are few studies analyzing a sole factor's impact on housing prices. This paper contributes to these two aspects. Maynard Smith and Price (1973) introduce biological evolution to game theory when studying the conflict and cooperative behavior of natural animal populations. They first propose the concept of evolutionary game. Nowadays, this method has been widely used to analyze and explain people's behaviors under specific circumstances. The formation of school-district housing prices is a process of continuous game among purchasers, which gradually approaches stable. Evolutionary game theory describes the process very well. ${ }^{[1-10]}$

\section{An Evolutionary Game Model}

Not every housing demander needs a unit of housing located in a school district. Only those who have school-age children consist of the demand in the school-district housing market. These people are regarded as a whole group called school-district housing demander population (hereafter called 'population'). ${ }^{[11]}$ The population accounts for only a small proportion in the society. The behaviors of the population influence school-district housing prices without impact on prices of other housing.

It is assumed that except for school district, all commercial housing are exactly the same in all aspects. The area of each unit is $d$. Suppose each family has only one child. This assumption captures China's one-child policy. Ownership of one unit of housing in a school district extra benefits the owner with an admission ticket to a high-quality school. For school-district housing, families' act of purchase enables their only child to free entry to a good school. It is assumed that one more school-district housing does not provide any extra utility for households. So in equilibrium, family demands one unit of school-district housing. ${ }^{[12]}$

For any individual, there are two alternative strategies. ${ }^{\alpha}$ denotes purchasing one unit of school-district housing while ${ }^{\alpha_{2}}$ denotes purchasing one unit of non-school-district housing. 
Purchase process can be regarded as a non-cooperative game played by two individuals randomly selected from the population. If both players purchase non-school-district housing (both choose strategy $\alpha_{2}$ ), the housing price will be $c$ per unit. Each player is required to pay $c$ for housing payment. Each owns one unit of commercial housing valued $c$ and has a zero profit. If one player purchases one unit of school-district housing while the other purchases one unit of non-schooldistrict housing, the housing price will be $c$ per unit. Each player pays $c$ for housing payment and owns one unit of commercial housing valued $c$. Moreover, the player who purchases school-district housing obtains an admission ticket to a high-quality school, and his counterpart has nothing extra. Obviously the former benefits more than the latter.

What if both players purchase school-district housing? Theoretically the value of an admission ticket can be quantified. For households who purchase school-district housing, it is the high-quality primary education that they actually purchase. Education is an investment in human capital. Highquality education usually relates to high expected return. And that is what parents truly concern about. A normal child with average ability accumulates human capital by receiving education and training. Through education and training, his human capital accumulates and expected income raises. The better the education children receive, the higher their expected income will be. Therefore, the value of an admission ticket to a high-quality school rather than a normal one can be measured by the increasing part of students' expected income resulting from the improvement of education's quality. If the increasing part of expected income exceeds the premium that equals to school-district housing prices subtracting non-school-district housing prices, households will definitely purchase school-district housing. Theoretically, expected income on education can be measured by accumulative present value of income that permanently improved by education. Because different income reflects different qualities of education and training people receive. Nevertheless it is difficult to estimate the present value of income that permanently improved by education. In order to approximately measure the expected income, I use the school selection fee (called Zexiao Fee in Chinese) to substitute it. Due to the nearby-admission policy, every schoolage child has been assigned a primary school and secondary school in accordance with his residence of Hukou. School selection fee is charged by the school when a school-age child who does not qualify to study in the school but want to be admitted. It is the cost of an improvement in education's quality. Since cost usually equals to benefits. School selection fee can be viewed as the expected return that a normal child obtains through better education and training. In the past, school selection fee did use to act as an admission ticket to local key primary and secondary schools. The better the school, the higher the selection fee. The difference between selection fees reflects the different qualities of education schools provide. ${ }^{[13-15]}$

Suppose that any school-age child must pay selection fee $A$ for admission to a school if he does not qualify to study there. An admission ticket to the school values $A$. In the game, if both players purchase school-district housing, the housing price will rise from $c$ per unit to $g$ per unit. Both players pay $g$ as housing payment. Note that $g$ is called the school-district price penalty value. It describes the theoretically maximum price that possibly appears. When $c+A-g \geq 0$, it is a dominant strategy to purchase one unit of school-district housing. Therefore it is always assumed that $c+A-g<0$. When both players purchase school district housing, each pays $g$ and owns one unit of housing valued $c$. And each obtains an admission ticket valued $A$. The profit for each is $c+A-g$ which is less than zero.

The following table is the evolutionary game matrix: 
Table 1 Evolutionary Game Matrix

\begin{tabular}{|l|c|c|c|}
\hline \multicolumn{2}{|c|}{} & \multicolumn{2}{|c|}{ one purchaser in population } \\
\cline { 3 - 4 } \multicolumn{2}{|c|}{} & $\alpha_{1}$ & $\alpha_{2}$ \\
\hline $\begin{array}{l}\text { the other } \\
\text { one in } \\
\text { populatio } \\
\mathrm{n}\end{array}$ & $\alpha_{1}$ & $(c+A-g, c+A-g)$ & $(A, 0)$ \\
\cline { 2 - 4 } & $\alpha_{2}$ & $(0, A)$ & $(0,0)$ \\
\hline
\end{tabular}

In the above model, suppose that players choosing strategy ${ }^{\alpha}$ account for $x$ proportion of the population, while the rest choosing strategy $\alpha_{2}$ account for $1-x$. The average profit of a player who chooses strategy $\alpha_{1}$ is:

$$
(c+A-g) x+A(1-x) .
$$

Since a player who chooses strategy ${ }^{\alpha_{2}}$ gets zero as average profit, in a stable state, the two are supposed to be equal. So,

$$
\begin{gathered}
(c+A-g) x+A(1-x)=0 \\
x=\frac{A}{g-c} \in(0,1)
\end{gathered}
$$

If the parameters $c, A$, and $g$ are known, the evolutionary stable strategy can be easily calculated from the above equation.

As long as equation $c+A-g<0$ stands, it is unlikely that all players choose strategy $\alpha_{1}$. In that case, players choosing strategy ${ }^{\alpha_{1}}$ lose money. Players choosing strategy ${ }^{\alpha_{2}}$ have zero profit which is better than loss. This behavior will diffuse in the population. Similarly, it is unlikely that all players choose strategy $\alpha_{2}$. In that case, players choosing strategy $\alpha_{2}$ have zero profit while the counterparts have $A . A$ is better than zero so this behavior will diffuse in the population. Suppose that the evolutionary stable strategy in the population is $(\bar{x}, 1-\bar{x})$. It means, under the stable state, the ratio of players who purchase school-district housing to those purchasing non-school-district housing is $\bar{x}:(1-\bar{x})$. It also interprets that, for any player, in the stable state the probability that he chooses strategy $\alpha_{1}$ is $x$, that he chooses strategy $\alpha_{2}$ is $(1-x)$.

\section{Price Penalty Coefficient and the Algorithm}

The school-district housing price penalty value ${ }^{g}$ represents the theoretically maximum housing price that results from looting behavior. In general, it does not occur. No one knows how much it is exactly. The higher the price penalty value, the more the households concern about school district. The school-district housing price penalty value ${ }^{g}$ reflects the absolute value of the extent that households concern about school district. And the coefficient as follows:

$$
r=\frac{g}{c}(>1)
$$

reflects the relative value of the extent that households concern about school district. This coefficient can be used to compare the different extents that households concern about school district in different regions. Due to the difficulty in obtaining $g$, it works out to think reversely. If the evolutionary stable strategy $(\bar{x}, 1-\bar{x})$ is known, it can be got:

$$
g=c+\frac{A}{\bar{x}} \text {. }
$$


Thus, the school-district housing price penalty coefficient is:

$$
r=\frac{g}{c}=1+\frac{A}{c \bar{x}} \text {. }
$$

In this way, the impact of school district on housing prices in different regions can be compared. The evolutionary stable strategy $(\bar{x}, 1-\bar{x})$ can be approximately estimated through market surveys, namely a survey on consultants of real estate agency and Delphi method.

Market-clearing prices never form at one time. Prices vary all the time. When households increasingly concern about school district, housing transactions become active and prices go up. In turn rising housing prices restrain the activity of transactions. When benefits and costs of purchasing school-district housing equal, a stable state forms. In this state, there is no difference between purchasing school-district housing and non-school-district housing. As long as the proportion $\bar{x}$ in the population is obtained, the price penalty coefficient $r$ can be estimated. It is a feasible approach to evaluate and compare the impact of school district on housing prices in different regions.

\section{An Example}

The following is an example which illustrates how to use the price penalty coefficient to compare the extents of the effect of school district on housing prices in different regions.

Assume that a first-tier city has a secondary school $S_{F}$, and a second-tier city has a secondary school $S_{s}$. Both schools are local key middle schools. The average price of non-school-district housing in the first-tier city is 58500 yuan per square meter. The selection fee of school $S_{k}$ is 200000 yuan per student. The average price of non-school-district housing in the second-tier city is 7850 yuan per square meter. The selection fee is 50000 yuan per student. By conducting surveys, 47 out of every one hundred households who have demand for school-district housing do purchase school-district housing in the first-tier city. Its counterpart in the second-tier city is 78. Suppose the average area of one unit of housing is 100 square meters in both cities. The question is in which city school district has more impact on housing prices.

In the first-tier city, $c_{F}=5850000, A_{F}=200000, \bar{x}_{F}=0.47$ :

$$
r_{F}=1+\frac{A_{F}}{c_{r} \bar{x}_{F}}=1+\frac{200000}{5850000 \times 0.47}=1.0727 \text {. }
$$

In the second-tier city, $c_{5}=785000, A_{s}=50000, x_{s}=0.78$ :

$$
r_{s}=1+\frac{A_{s}}{c_{s} \bar{x}_{s}}=1+\frac{50000}{785000 \times 0.78}=1.0817
$$

Since $r_{F}=1.0727>r_{S}=1.0817$, in the second-tier city school district has more impact on housing prices than it does in the first-tier city.

\section{Conclusion}

There are many complicated factors affecting housing prices through complex channels. Sometimes one factor plays a major role sometimes a few play key roles together. In the past two decades, China's overall housing prices kept rising. So far, housing prices in many cities have already gone through increases to over ten times. It can be described as skyrocketing. Rising prices bring households joy and anxiety. People feel delightful for appreciation of properties. But huge financial risks and high leverage ratio in both corporate sector and household sector make them worried about the economic crisis and the development of real economy. A common question often being asked is whether housing prices slump. In order to answer this question, one should figure out clearly how and when, what factor influences housing prices. ${ }^{[16]}$ Only in this way can governments effectively regulate housing markets and guide the macroeconomic to a healthy sustainable 
development.

It is not easy to analyze the impact of a sole factor on housing prices, and this paper makes contribution to that. It proposes the definition and algorithm of a sole factor's housing price penalty absolute value and coefficient. They can be used to analyze and compare the effect of a sole factor on housing prices.

\section{References}

[1] Tiebout, Charles M. A Pure Theory of Local Expenditures[J]. Journal of Political Economy, 1956, 64(5): 416-424.

[2] Oates, W. E. The Effects of Property Taxes and Local Public Spending on Property Values: An Empirical Study of Tax Capitalization and the Tiebout Hypothesis[J]. Journal of Political Economy, 1969, 77(6): 957-971.

[3] Black, Sandra E. Do Better Schools Matter? Parental Valuation of Elementary Education[J]. The Quarterly Journal of Economics, 1999, 114(2): 577-599.

[4] David M. Brasington. Edge versus center: finding common ground in the capitalization debate[J]. Journal of Urban Economics. Volume 52, Issue 3, November 2002, Pages 524-541.

[5] Chin, H. and Foong, K. Influence of School Accessibility on Housing Values [J]. Urban Plann. Dev., 10.1061/(ASCE) 0733-9488 (2006) 132:3(120), 120-129.

[6] Davidoff, I. and Leigh, A. How Much do Public Schools Really Cost? Estimating the Relationship between House Prices and School Quality[J]. Economic Record, 2008, 84: 193206.

[7] Christian A.L. Hilber and Christopher Mayer. Why do households without children support local public schools? Linking house price capitalization to school spending[J]. Journal of Urban Economics. Volume 65, Issue 1, January 2009, Pages 74-90.

[8] WEN Hai-zhen, YANG Shang and QIN Zhong-fu. The Impact of Educational Facilities on Housing Price: An Empirical Analysis from the Perspective of the Capitalization for Public Goods[J]. China Land Science, 2013, 01:34-40.

[9] MA Jun, LUO Hong-juan and ZHANG Tie-sheng. Empirical Study of the Influence of Elementary Education Resources on Housing Price[J]. Journal of Anhui University of Technology (Social Sciences), 2013, 06:16-18.

[10]FENG Hao and LU Ming. School Selection by Housing Purchase: Empirical Evidence of Education Influencing Housing Prices and Policy Implication [J]. The Journal of World Economy, 2010, 12: 89-104.

[11] HU Wan-yang, ZENG Si-qi and WANG Rui. The Capitalization of School Quality in Home Value: A Matching Regression Approach with Housing Price-Rent Comparison[J]. China Economic Quarterly, 2014, 03:1195-1214.

[12] WANG Wei, YANG Hong, SUN Wei and GU Wei-zhe. A Study on the Spatial and Temporal Effects between School District and the Value of Residential Based on Hedonic Model[J]. Statistics \& Information Forum, 2014, 09: 72-78.

[13] SHI Yi-shao and WANG Yi-ting. The Impacting Mechanism of Housing Prices in the School Districts in Shanghai City[J]. China Land Sciences, 2014, 12:47-55.

[14]ZHANG Hao, LI Zhong-fei and DENG Bai-jun. Educational Resource Allocation Mechanism and Housing Prices: An Empirical Analysis of Education Capitalization in China[J]. Journal of Financial Research, 2014, 05: 193-206.

[15] LIU Run-qiu and SUN Xiao-ya. The Effect of Education Quality Capitalization on Housing Prices Based on Empirical Analysis of Elementary School District of Wuhou District in Chengdu[J]. Finance \& Economics, 2015, 08: 91-99.

[16] LU Wei-min and ZHANG Lin-wei. The Root of School District Housing Problem and Analysis of Countermeasures[J]. Research in Educational Development, 2015, Z2:13-17. 